\title{
PASCAL E A ORDEM DA CONCUPISCÊNCIA
}

\author{
Maria Isabel Limongi* \\ belimongi@yahoo.com.br
}

RESUMO Pascal concebe a ordem civil como uma ordem da concupiscência, isto é, uma ordem que é produzida e regulada pela concupiscência. Trata-se aqui de mostrar a novidade dessa idéia relativamente à tradição do pensamento político e a Santo Agostinho, para em seguida apontar o que parece ser a sua condição de possibilidade, a saber, o modo como Pascal concebeu a vontade decaída e, mais propriamente, a concupiscência da carne, à qual se reporta a ordem civil.

Palavras-chave Pascal; Ordem da Concupiscência; Vontade

ABSTRACT Pascal conceives the civil order as an order of conscupiscence, that is, an order produced and regulated by concupiscence. We shall present the novelty of this idea vis-a-vis the tradition of political thought and St. Agustine, and point out what seems to be its condition of possibility, that is, the way Pascal conceived the fallen will and, more properly, the concupiscence of flesh, to which refers the civil order.

Keywords Pascal; Order of Concupiscence; Will

\footnotetext{
* Professora da Universidade Federal do Paraná. Artigo recebido entre $1^{\circ}$ e 30 de abril de 2006 e aprovado
} entre $1^{\circ}$ e 31 de maio de 2006.

KRITERION, Belo Horizonte, $n^{\circ}$ 114, Dez/2006, p. 321-334. 
Pascal concebe a ordem civil como uma ordem da concupiscência, isto é, uma ordem que é produzida e regulada pela concupiscência. A expressão "ordem da concupiscência", empregada por P. Sellier para designar um dos tópicos de aproximação entre Pascal e Agostinho, ${ }^{1}$ salvo engano, não é utilizada por Pascal, mas a idéia que ela condensa é claramente indicada por ele, por exemplo, nos fragmentos P 106-146 e P 118-423 dos Pensées $^{2}$ nos quais se diz, respectivamente, que da concupiscência se retirou uma "bela ordem" e um "regulamento admirável": trata-se precisamente da ordem civil.

Entretanto, ao aproximar nesse aspecto Pascal e Agostinho, P. Sellier parece perder de vista o que há de novo e decisivo na idéia pascaliana da ordem civil enquanto uma ordem da concupiscência, a saber, que possa haver ordem civil sem a ação da virtude. Não há um correspondente dessa idéia na tradição política em cujas águas Pascal bebeu, nem mesmo em Agostinho. Gostaríamos aqui de apresentar essa novidade e de expor o que nos parece ser a sua condição de possibilidade, a saber, o modo como Pascal concebeu a vontade decaída e, mais propriamente, a concupiscência da carne, à qual se reporta a ordem política.

\section{I}

Para Maquiavel e Hobbes, por assim dizer a vanguarda do pensamento político no tempo de Pascal, a sociedade política é ordenada e justa na exata medida em que é o resultado de uma ação ordenadora, compreendida como virtude. Sem a ação da virtù, em Maquiavel, os conflitos humanos resultam em desordem; sem a virtude dos homens racionais, que percebem a necessidade de instituir a ordem política a partir do ato contratual, as relações humanas tendem a se degradar para Hobbes numa guerra de todos contra todos. Para Maquiavel e Hobbes, cada um a seu modo, não há ordem política sem uma ação que a institua enquanto tal, e que, na medida mesma em que é capaz de ordenar o campo social e político, é considerada virtuosa.

Para Agostinho, seguramente uma fonte importante de Pascal ao lado de Maquiavel e Hobbes, tampouco pode haver ordem e paz social sem a ação da virtude. Isso é evidente quanto à sociedade dos homens que formam a cidade de Deus, a sociedade plenamente justa, onde a paz é perfeita e certa:

1 Cf. Sellier (1970).

2 Os fragmentos dos Pensamentos serão indicados no corpo do texto com um 'P' seguido de sua numeração na edição Lafuma e na edição Brunschvicg, respectivamente. De modo geral, as citações seguem a tradução de Mario Laranjeira em Pascal (2001). 
tal sociedade encontra na própria justiça e na verdadeira virtude o seu princípio ordenador. O mesmo não se passa com a cidade dos homens, a sociedade dos ímpios e dos injustos, a quem falta a graça da caridade e da justiça. Isso não implica, contudo, que a cidade dos homens de Agostinho possa ter ordem sem a ação da virtude, como parece ser o caso da ordem da concupiscência de Pascal.

Segundo Agostinho, a cidade dos homens, mesmo injusta, é ainda assim uma cidade, pois onde houver "um grupo de seres racionais numa comunidade harmoniosa em torno de objetos amados" há um povo, uma res publica, e, portanto, uma cidade. ${ }^{3}$ Faz sentido, assim, falar numa cidade dos homens, na medida em que os homens podem formar um povo em torno do amor que possuem em comum pelas coisas terrenas. A cupiditas fornece desse modo à cidade dos homens o princípio de sua unidade. Ainda assim, a cidade terrestre de Agostinho, à diferença da ordem da concupiscência de Pascal, não constitui uma ordem senão pela ação da virtude.

Pois, se compreendermos a cidade dos homens como uma entidade mística reunindo o conjunto dos infiéis predestinados ao sofrimento eterno, ${ }^{4}$ não se pode dizer dessa cidade que nela se viva em paz, no sentido de uma "concórdia ordenada". ${ }^{5} \mathrm{O}$ amor pelas coisas terrenas, quando não subordinado ao amor a Deus, é injusto e desconforme à ordem da natureza e à hierarquia das coisas. Ele não pode, portanto, fundar uma vida comum ordenada e harmoniosa, ainda que reúna os homens num destino comum. Se a cidade dos homens guarda alguma proporção com a justiça e a ordem é apenas na medida em que sua desordem é abarcada por uma ordem maior, que a regula desde o exterior por um princípio sumamente justo. Tomada nela mesma e segundo sua

3 La Cité de Dieu, XIX, 24. Veja-se o comentário de E. Gilson ao movimento argumentativo de Agostinho em $A$ cidade de Deus XIX, 21-24, em que a definição de república adotada por Cícero, segundo a qual um povo é "uma multidão reunida e organizada em torno do consentimento ao direito e de um interesse comum" [La Cité de Dieu, XIX, 21] é substituída por esta, permitindo a Agostinho dizer que Roma foi uma cidade apesar de faltar-Ihe a justiça em sentido estrito. "Interpretada por um cristão a fórmula de Cícero deixava lugar para um só povo: o povo cristão, detentor da única justiça verdadeira, a de Cristo. A nova fórmula permite ao contrário reconhecer povos dignos desse nome, ainda que injustos" (GILSON, 1952, p. 45).

4 Segundo Gilson, esse é o verdadeiro sentido da noção, não se devendo confundir "a cidade terrestre com as sociedades políticas enquanto tais, ou, como se diz por vezes, com o Estado" (GILSON, 1952, p. 54). Estrito senso, a cidade terrestre, assim como a celeste, se define pelos membros que a compõem, ainda que "Agostinho se exprima sobre esse ponto de tantas maneiras diferentes que os leitores justificadamente hesitem e certos intérpretes se percam. Um fio condutor permite, contudo, nos situarmos com segurança no labirinto dos textos. Trata-se do princípio diversas vezes posto por Agostinho de que as duas cidades de que ele fala recrutam seus cidadãos segundo a lei da predestinação divina. Todos os homens fazem parte de uma ou de outra, porque todos os homens são predestinados à felicidade com Deus, ou à miséria com o demônio" (GILSON, 1952, p. 52).

5 La Cité de Dieu, XIX, 13. 
constituição própria, não há ordem e justiça na cidade dos homens, entendida como a sociedade dos predestinados ao sofrimento eterno.

Se, em contrapartida, compreendermos a cidade dos homens como uma sociedade concreta historicamente constituída, uma organização mundana, estabelecida por homens que se mundanizaram e criaram, a partir de seu amor pelas coisas terrenas, um mundo comum na terra,${ }^{6}$ de tais sociedades - de uma delas ao menos, tal o caso de Roma - pode-se dizer que ela é internamente justa, isto é, que ela se institui a partir de um princípio justo.

Agostinho louva os romanos ou alguns deles, que viveram num certo período da história de Roma após a expulsão dos tarqüíneos, por terem colocado o amor à pátria acima do amor a si mesmos, reputando a essa virtude o esplendor de Roma. "Eles não hesitaram em colocar a pátria à frente de si mesmos, e, em razão deste único vício, o amor à glória, reprimiram o desejo ávido de riquezas e uma série de outros vícios." ${ }^{"} \mathrm{O}$ amor pela glória terrestre é seguramente um vício, mas o amor pela pátria, posto à frente do amor de si, é em si mesmo virtuoso e justo. Tanto é assim que este amor deve servir de exemplo ao cristão: "se pela glória da cidade de Deus não praticarmos virtudes de algum modo semelhantes as que os romanos praticaram pela glória da cidade terrestre, sejamos devorados pela vergonha". ${ }^{8}$

Compreende-se que possa haver virtude entre os pagãos levando-se em conta que a queda enfraquece a natureza humana, em si mesma virtuosa, mas não desnatura inteiramente o homem. ${ }^{9}$ Onde há uma natureza, ainda que degradada e enfraquecida, há virtude, pois toda natureza é em si mesma boa. Onde há no mundo uma vida em relativa paz e tranqüilidade, isso se deve ao que resta nos homens de virtude e justiça, resquícios de sua primeira natureza. ${ }^{10}$

6 Nas passagens supra mencionadas em que Agostinho, reformulando a definição de Cícero, precisa em que sentido se pode falar de uma cidade dos homens, o que está em questão é precisamente o fato de se poder atribuir a Roma, isto é, a uma certa organização mundana historicamente constituída, uma unidade tal que ela mereça o nome de cidade.

7 La Cité de Dieu, V, 13.

8 La Cité de Dieu, V, 18.

9 "A imagem de Deus não foi totalmente destruída na alma humana pela mancha dos afetos terrenos a ponto de não terem permanecido alguns vestígios embora débeis. Pode-se dizer que os maus, mesmo em sua vida ímpia, cumprem e amam alguns preceitos da Lei" (O Espírito e a Letra, 28.48).

10 H.-X. Arquillière nota que, embora haja em Agostinho uma tendência para subordinar o domínio da natureza ao domínio da graça, na medida em que a justiça é pensada como um dom de Deus (graça), inalcançável pela natureza decaída, há na obra de Agostinho um espaço reservado para a noção de direito natural: "é certo que Agostinho se compraz em contrastar vigorosamente as duas cidades e a em acentuar o antagonismo. Mas isso não significa que ele jamais perceba entre elas uma região intermediária e um meio termo, a do direito natural, das virtudes naturais, instáveis, frágeis e incompletas sem dúvida, mas não imaginárias e impossíveis". (ARQUILLIĖRE, 1972, p. 64) 
Assim, para Agostinho, tanto na cidade celeste como na terrestre, há concórdia ordenada onde houver a ação da virtude - seja por intermédio da graça, como na cidade de Deus, seja como resquício de uma natureza virtuosa não totalmente apagada pelo pecado, como em certos reinos terrestres relativamente bem ordenados, tais como Roma. Não há, portanto, em Agostinho algo semelhante à ordem da concupiscência de Pascal, em que a concupiscência se faz um princípio ordenador, produzindo ordem e paz social sem virtude.

\section{II}

A diferença entre Pascal e Agostinho pode ser reconduzida à diferença no modo como compreendem o preceito segundo o qual o pecado nos fez servos da carne, incapazes de vencer a concupiscência.

Para Agostinho, a vontade é uma faculdade da alma racional, pela qual ela realiza o fim de toda criatura que é o de reconduzir-se ao Criador. Todas as criaturas tendem a Deus, mas para as almas racionais a realização dessa tendência depende de uma escolha de seu livre-arbítrio. ${ }^{11}$ Daí porque a felicidade que advém dessa escolha, bem como a infelicidade que se segue do afastamento voluntário de Deus, ser recompensa e castigo, isto é, a aplicação de um princípio de justiça e não o simples resultado de uma necessidade natural. "Se o homem carecesse de livre-arbítrio da vontade, como poderia existir esse bem, que consiste em manifestar a justiça, condenando o pecado e premiando as boas ações?"'12

Em decorrência do pecado, porém, e como o seu castigo, o homem não é mais capaz de abraçar a Deus a partir tão-somente de sua vontade. A vontade tornou-se impotente para sustentar, sem o auxílio da graça, a dinâmica natural que conduz o homem a Deus. Mas isso não porque sua natureza tenha se transformado ou porque o homem tenha perdido o seu livre-arbítrio, de cuja escolha depende ainda o seu encontro com Deus. O livre-arbítrio é o mesmo. O seu poder de escolha, porém, encontra-se diminuído em função do pecado - daí sua impotência.

Querer e poder, esclarece Agostinho, são faculdades distintas: podemos querer algo e não o poder ou poder algo e não o querer. ${ }^{13}$ A primeira disjunção

11 Sobre a dinâmica da natureza como pano de fundo da concepção agostiniana da vontade cf. "Vontade e Contra-vontade" (NOVAES, 2002).

12 O livre arbítrio, II, 1, 3.

13 O Espírito e a Letra, 31.53. 
é a que ocorre ao pecador. Ele quer ser feliz e dispõe de uma vontade de cuja livre-escolha depende sua felicidade. Mesmo sendo pecador, ele pode querer abraçar a Deus, reconhecendo-o como o bem supremo. Mas para que seja esta a sua vontade, é preciso que ele possa ver em Deus o sumo bem e que seja capaz de manter-se firme nessa visão. Precisamente isso, contudo, escapa ao seu poder. "Não está no poder de ninguém escolher que coisa deve vir à sua mente, embora seja um poder da vontade consentir ou não." ${ }^{14} \mathrm{O}$ que está em questão não é o fato de que os conteúdos mentais dependam de uma causalidade externa à mente, como alguém poderia ser tentado a supor, mas o fato de que o grau de distinção com que esses conteúdos são discernidos pela mente depende de uma luz que lhe é superior e transcendente - a luz da Verdade, que é o próprio Deus, na qual reside a regra sem a qual tais conteúdos não podem ser bem discernidos e corretamente julgados. Ou seja: o que está em jogo é que o poder de julgar e de ver com propriedade os objetos sobre os quais recai a escolha da vontade depende diretamente de Deus ou da própria Verdade. ${ }^{15}$ Daí porque o pecador, que deu as costas à luz divina e por conseguinte não mais discerne com justeza os objetos, tenha o seu poder de escolha diminuído, de modo a não mais poder exercer o seu livre-arbítrio com plena liberdade, se Deus não iluminar suas escolhas pela graça.

A distância entre o querer e o poder é, assim, o que explica que a vontade tenha se tornado impotente para conduzir o homem a Deus, sem contudo deixar de ser um livre-arbítrio, de cuja escolha depende ainda a realização desse fim. O que resta no homem do poder de bem discernir os objetos de sua vontade é o que lhe resta das virtudes de sua primeira natureza, enfraquecidas, mas não totalmente apagadas pela queda. Daí porque o homem decaído, mesmo concupiscente, possa ainda imprimir, no mundo para o qual voltou sua vontade, a marca de suas virtudes.

Pascal, porém, compreende de outro modo a diferença entre o estado do homem antes e depois da queda. Não se trata mais simplesmente de dizer, com Agostinho, que o pecador tem enfraquecido o seu poder de discernir o que deve escolher, mas que isso ocorre, porque a sua vontade perdeu o poder de escolher. A vontade não é mais a mesma. Ela adquiriu uma nova natureza, sob o signo da qual já não pode mais stricto sensu ser virtuosa.

Após a queda, esclarece-nos os Escritos sobre a Graça, a vontade se encontra "atraída para (attirée vers) a criatura"16 - e Pascal utiliza a imagem

14 O Espírito e a Letra, 34.60

15 Cf. O Livre arbítrio, II, XII, 33-34.

16 Pascal (1963, p. 317). 
de uma força física para caracterizar essa atração: ${ }^{17}$ a vontade é atraída pela concupiscência como um corpo é puxado por uma corda. A analogia lhe permite mostrar que mesmo quando a vontade, pela graça, passa a ser atraída para Deus, ela não recobra sua condição anterior; quando Adão ainda podia encontrar a justiça ou dela se afastar "sem ser forçado, nem atraído de uma parte ou outra".$^{18}$ Pois a Adão "bastava conhecer o bem para poder se dirigir a ele". ${ }^{19}$ Sua vontade era maleável ao que seu espírito lhe apresentava como um bem, deixando-se guiar por ele. Essa maleabilidade, contudo, foi perdida com o pecado; e a vontade, que antes escolhia com base no conhecimento dos objetos, vê-se agora atraída por eles, como que por uma força.

"A concupiscência tomou seus membros, excitou (a chatouillé) e deleitou sua vontade no mal. ${ }^{20}$ Essa excitação, esse deleite é o que se acrescentou à vontade. Antes da queda, Adão "não sentia nenhum deleite". ${ }^{21}$ Após a queda, o homem deleita-se com o mal, encontra prazer nele. E "o que há de mais claro que essa proposição, que nós fazemos sempre o que nos deleita mais?"22 Encontrar deleite no mal implica, portanto, fazer o mal. Não há alternativa, somos determinados a escolher o que mais apraz. Se antes da queda Adão escolhia, não é porque escapasse à aplicação dessa lei, mas porque os objetos lhe eram indiferentes do ponto de vista do deleite que despertavam e, conseqüentemente, sua vontade não sofria nenhum tipo de atração por eles. $\mathrm{O}$ homem decaído, porém, deleita-se com certos objetos, que lhe despertam uma sorte de excitação sensível - um chatouillement - e que atraem sua vontade de um tal modo que ela não pode deixar de voltar-se para eles. A vontade encontra-se "ligada (liée) pelo deleite". ${ }^{23}$ Daí porque a graça seja compreendida não mais como a iluminação da escolha, mas como contra-determinação da vontade: o homem "não pode ser liberado do pecado senão por um deleite mais forte que o torna escravo da justiça". ${ }^{24}$

Essa vontade transformada pela queda, essa vontade "ligada pelo deleite" e sem medida comum com a virtude é o princípio da ordem civil. 


\section{III}

Para compreender a distância que separa as ações da virtude das operações da concupiscência, convém recorrer à doutrina pascaliana das ordens, a partir da qual se poderá ainda precisar o sentido da expressão "ordem da concupiscência" de que partimos. Pois pode-se dizer da ordem civil que ela é uma ordem da concupiscência não apenas porque é bem regulada e pacífica, mas por assim ser a partir de um princípio ordenador - a concupiscência -, no plano próprio em que esse princípio está apto a produzir efeitos ordenados, a saber, na ordem do corpo.

Como se sabe, há para Pascal três ordens diferentes em gênero: a ordem do corpo, do espírito e a da caridade (ou da vontade). ${ }^{25}$ Tais ordens são ordens de grandezas distintas e incomensuráveis, no sentido matemático do termo: assim como "não se aumenta uma grandeza contínua quando se lhe acrescenta, tanto quanto se queira, grandezas de uma ordem inferior"; assim como "o ponto não acrescenta nada à linha" e "as raízes não contam relativamente aos quadrados", ${ }^{26}$ uma grandeza do corpo é nula e não tem nenhum valor nas ordens superiores do espírito e da caridade; daí ser "inútil a Arquimedes mostrar-se como príncipe em seus livros de geometria, embora ele o fosse", ou a "Jesus Cristo, para brilhar em seu reino de santidade, vir como rei, embora tenha vindo realmente com o brilho de sua ordem" (P 308-793). A ciência de Arquimedes é uma grandeza da ordem do espírito, a sabedoria de Cristo uma grandeza da caridade, grandezas de ordens superiores em relação as quais as grandezas do corpo são desprezíveis.

Mas as grandezas de cada ordem não diferem apenas quanto aos seus valores incomensuráveis e hierarquizados. Elas se distinguem também enquanto potências determinadas, capazes de produzir certos efeitos segundo operações específicas, próprias a cada ordem: "todos os corpos juntos não poderiam levar a nenhum pensamento, por pequeno que seja. Isto é impossível e de outra ordem. De todos os corpos e espíritos não se poderia retirar um movimento da verdadeira caridade. Ela está numa ordem infinitamente mais elevada" (P 308-793). A incomensurabilidade dos valores de cada ordem tem como contrapartida o fato de que aquilo que opera e produz efeito numa ordem não é capaz de operar e produzir efeitos em outra. ${ }^{27}$

25 Sobre o tema das três ordens, ver, especialmente, P 308-793 e P 933-460. Sobre a importância e centralidade do tema ver Mesnard (1988), Lazzeri (1993, parte 2, cap. IV) e a coletânea de artigos Les "trois ordres" de Pascal publicada na Révue de Métaphysique et de Morale (1997).

26 Pascal (1963, p. 94).

27 Como mostra M. Pércheman (1997), "a diferença genérica entre duas ordens, quando comandada pela consideração das grandezas, é uma heterogeneidade que deve ser compreendida pela incomparabilidade 
A partir desse esquema geral podemos compreender a transformação da vontade resultante da queda como o resultado de um reordenamento da vontade. É como se a vontade, ao pecar, mudasse de ordem, deixando de se inscrever em sua ordem própria, na qual opera de modo livre e dinâmico, para se inscrever na ordem do corpo, cujo modus operandi não é dinâmico, mas mecânico. Essa inscrição da vontade na ordem do corpo explica que ela tenha deixado de tender a seus objetos como a fins livremente escolhidos por ela (o que a vontade agostiniana jamais deixa de fazer), deixando-se atrair pelo que a deleita.

A vontade, é verdade, se é que muda de ordem, não chega com isso a perder totalmente suas propriedades dinâmicas. Ela guarda ainda algum dinamismo de sua primeira natureza, pois é ainda uma tendência, a busca de um fim, que é a felicidade. ${ }^{28}$ Seus atos tampouco deixam de ser voluntários, isto é, atos que se referem a uma faculdade de escolha, mesmo que perdida. Pois a concupiscência é ela mesma o produto de uma escolha e seus atos pautam-se ainda pela representação da felicidade que determinou essa primeira escolha. Ceder à concupiscência não é, pois, o mesmo que ceder a uma força (Cf. $\mathrm{P}$ 97-334).

Ainda assim, pode-se dizer da concupiscência, ao menos da concupiscência da carne, que ela opera de modo mecânico e não mais dinâmico. Pois ela não mais escolhe segundo representações, mas é atraída por representações - e por representações de uma natureza particular, as representações de um espírito ele mesmo decaído e inscrito na ordem do corpo, de um espírito que é imaginação. Tudo se passa, assim, como se a vontade, em função de sua inscrição na ordem do corpo, passasse a operar de um modo que não é o seu e que é incompatível com o que faz dela uma vontade. Nesse processo, não há apenas o enfraquecimento de uma capacidade de escolha, mas a contradição interna dessa faculdade, que agora se deixa determinar desde o exterior. A contradição está em ser a vontade a potência de uma ordem operando segundo o modo de outra, em ter a vontade se tornado, portanto, uma outra potência. Os dois principais fragmentos que tratam da diferença entre as ordens, lidos em conjunto, sustentam essa interpretação.

entre potências. As grandezas são potências ativas e a heterogeneidade das ordens redunda na desproporção entre potências ativas determinadas e efeitos determinados". Sobre a importância de integrar à definição de ordem essa dimensão operativa da grandeza compreendida como potência, cf. Lazzeri (1993, parte 2, cap. IV, em especial, nota 3, p. 266).

28 "(...) Todos os homens buscam ser felizes. (...) Todos tendem a esse fim" (P 148-425). "(..) Eis aí o estado em que os homens estão hoje. Resta-lhes um vago instinto de felicidade da sua primeira natureza (...)" (P 149-430). 
O fragmento P 933-460, partindo da distinção tradicional entre as três concupiscências $^{29}$ - a da carne, a dos olhos e do orgulho -, apresenta a diferença entre as ordens como uma diferença entre três ordens de coisas - a carne, o espírito e a vontade - e distingue três tipos de homens - os carnais, os curiosos (ou instruídos) e os sábios - conforme eles "tenham por objetos" os corpos, os objetos do espírito ou a justiça. Assim, o que se sugere é que cada ordem de coisas é uma classe de objetos visados pela vontade, os homens distinguindose entre si pelos objetos que visam.

Além disso, se diz da vontade que ela é, por si mesma, uma ordem de coisas já que "existem três ordens de coisas: a carne, o espírito, a vontade". Há, assim, uma "ordem da vontade" à qual pertence a justiça, que não é outra coisa senão a vontade dirigida a Deus, assim como há uma ordem do espírito à qual pertencem os objetos do espírito, e uma ordem da carne à qual pertencem os corpos. Assim, em sua ordem própria - na ordem da vontade - o objeto da vontade é a justiça. Quando a justiça não é visada de modo apropriado (isto é, em Deus), engendra-se o orgulho, que pode então ser compreendido como um desvio do objeto da vontade no interior de sua própria ordem. Em contrapartida, as duas outras formas da concupiscência, a concupiscência dos olhos e a da carne, envolveriam algo mais. Nelas, a vontade parece mover-se para fora de sua ordem - para a ordem do espírito, na concupiscência dos olhos, e para a ordem do corpo, na concupiscência da carne. A concupiscência pode ser assim entendida, nesses casos, não como uma desordem da vontade no interior de sua ordem, mas como um movimento pelo qual a vontade passa a visar objetos pertencentes a outras ordens que não a sua.

O fragmento $\mathrm{P}$ 308-793, por sua vez, não fala mais em três ordens de coisas e, portanto, de uma diferença entre as coisas que se podem fazer própria ou impropriamente objetos da vontade, mas em três ordens diferentes em gênero, isto é, de uma diferença entre as ordens mesmas, enquanto três regiões ontológicas descontínuas: as ordens do corpo, do espírito e da caridade. ${ }^{30}$ Cada ordem é agora caracterizada como uma ordem de grandezas distintas e hierarquizadas, que produzem, de maneiras distintas, efeitos distintos e sem medida comum entre si. Mais ainda, cada ordem tem um modo próprio de produzir efeitos a partir de causas apropriadas.

Se "de todos os corpos e espíritos não se poderia tirar um movimento da verdadeira caridade" (P 308-793), isso se deve não apenas à impropriedade

29 Ver, nesse sentido, Mesnard (1988), que nos remete ao modo como a tradição agostiniana pensou esse tema a partir de São João, bem como o modo como Pascal, partindo dela, dela se afasta.

30 Sobre a diferença entre as perspectivas dos fragmentos, cf. Percheman (1997). 
da causa, mas também ao modo como ela produz seus efeitos. Pode-se talvez dizer que o modus operandi da ordem da caridade é dinâmico, em referência à operação da vontade que adere à justiça e a Deus como a um fim; que o modus operandi do espírito é a demonstração, tal como Pascal a descreve em Do espírito geométrico ${ }^{31}$ e que o modus operandi do corpo é mecânico, tendo em vista as inúmeras referências de Pascal ao corpo enquanto máquina. ${ }^{32}$ Parece assim razoável pensar que a concupiscência da carne (que não é a única forma de concupiscência, mas a que nos interessa por ser a que produz a ordem política) é o movimento da vontade que, ao escolher objetos da ordem do corpo, inscreve-se nessa ordem, passando a operar segundo o modo dos corpos.

Operar ao modo dos corpos, sendo ainda uma vontade, pode significar ao menos duas coisas. Em primeiro lugar, deixar-se guiar por representações que se formam no espírito de maneira mecânica. Pois, como adverte Pascal, "não devemos nos enganar, somos autômatos tanto quanto espírito" (P 821252). Ser autômato não é apenas ter um corpo, além de um espírito; é pensar, deixar-se discursivamente persuadir de modo não demonstrativo - a partir do corpo e no espírito como um corpo. Ser autômato é pensar maquinalmente, por força de uma repetição que impressiona e, desse modo, inclina o espírito. ${ }^{33}$ É pensar por costume.

O costume de ver os reis acompanhados de guardas, tambores, oficiais e todas as coisas que inclinam a máquina em direção ao respeito e ao terror faz com que sua feição, mesmo quando só e sem acompanhamentos, imprima em seus súditos o respeito e o terror, porque não separamos no pensamento suas pessoas do que vemos ordinariamente junto delas (P 25-308).

Ora, é por se estar sujeito à imaginação que se pensa como autômato e não apenas como espírito. Pois a imaginação não é apenas, para Pascal, uma faculdade que oferece à razão a matéria do pensamento. Ela é uma "soberba potência inimiga da razão" (P 44-82), um outro modo de pensar que não a razão e que, além disso, a controla e a domina. A imaginação põe "a razão fora do eixo" (P 44-82). Pode-se entender por isso a retirada do espírito para fora de sua ordem, a ordem da demonstração, pela qual a razão, furtando-se ao regime das determinações mundanas, abarca o mundo em pensamento: "pelo espaço

31 “(...) O coração tem sua ordem; o espírito tem a sua que é por princípio e demonstração (...)” (P 298-283). 32 Segundo Pascal, Descartes está certo ao afirmar que algo (cela) "se faz por figura e movimento", ainda que seja ridículo e inútil o propósito de "compor a máquina", precisando quais são tais figuras e movimentos ( $P$ 84-79).

33 Sobre o automatismo psicológico em Pascal, ver Desgrippes (1935), especiamente, cap. 1 e Apêndice II. 
o universo me compreende e engole como um ponto: pelo pensamento eu o compreendo" (P 113-348). Pôr a razão fora dos eixos é, assim, fazer com que o espírito desça ao mundo para submeter-se, de dentro dele - não mais, portanto, como razão, mas como imaginação - ao regime de suas determinações. Em mais de um momento Pascal se vale de imagens mecânicas para caracterizar o modo como a imaginação nos conduz: "razão engraçada essa que um vento maneja (manie), e em todos os sentidos. Eu relacionaria quase todas as ações dos homens que quase só se abalam pelos seus solavancos (secousses)" (P 4482). A imaginação, portanto, faz do pensamento uma espécie de mecânica das representações, submetendo-nos assim aos automatismos do costume. É deste modo que ela subverte a razão e a domina.

Ela não poderia fazê-lo, contudo, se não contasse com a cumplicidade da vontade. A vontade decaída se vê inevitavelmente comprometida com a imaginação, ela quer o que a imaginação lhe apresenta e não pode deixar de querer, posto que o "vestígio vazio de felicidade" deixado pela queda só pode ser imaginariamente preenchido (P 148-425). É o que ilustra o prazer do jogo, o modelo de todo prazer mundano. O que faz com que um jogador passe a vida jogando para ganhar uma pequena quantia que em si mesma não traria satisfação? Ele "precisa se animar e criar um engodo para si mesmo, imaginando que seria feliz ganhando aquilo que não quereria que the fosse dado sob a condição de não jogar, a fim de que forme para si um motivo de paixão e excite com isso o seu desejo" (P 136-139; grifo nosso). Como não se pode encontrar a felicidade, que está em Deus, nos objetos que deleitam a vontade, não há alternativa senão deixar-se determinar pela imaginação, imaginando que os prazeres sensíveis possam trazer a felicidade que de fato não trazem. ${ }^{34}$ De modo que a imaginação, como uma faculdade de ilusões, é o que em última instância move a vontade e, na medida em que é também uma faculdade de representar o mundo de dentro dele, aprisiona a vontade no regime das determinações mundanas.

Dizer que a vontade opera ao modo dos corpos significa ainda dizer, em segundo lugar, que ela produz um efeito que é da ordem do corpo. Esse efeito é a força de um partido dominante, o pilar da ordem civil.

Retomemos: a concupiscência nos prende à imaginação e ao costume. A imaginação e o costume, por sua vez, ao distribuir a reputação e legitimar as leis, estabilizam as relações de força entre os homens. "A força se mantém pela imaginação em determinado partido" (P 828-304). A força faz com que 
existam reinados; a fantasia faz com que fulano ou sicrano seja rei (Cf. P 767-306). E é porque significam e constituem em última instância a força do partido dominante que os signos imaginários da reputação não são vãos: ser elegante "é mostrar que grande número de pessoas trabalha para si. (...). Ora, não é uma simples superfície, nem simples arnês possuir vários braços. Quanto mais braços se têm, mais forte se é. Ser elegante é mostrar a própria força" (P 95-316). É, portanto, a força a razão última da ordem social e política: eis o ponto sobre o qual Pascal insiste nos fragmentos que tratam da relação entre a força e a justiça (P 81-299; P 85-878). Pois é a força, em última instância, a potência apropriada para produzir efeitos na ordem do corpo. No entanto, o efeito da força só pode ser a ordem civil quando, pela imaginação e pelo costume, aos quais nos prendemos por concupiscência e que passam a determinar os movimentos da concupiscência, a força se fixa num partido e se faz propriamente poder político.

Compreende-se assim que se possa falar de uma ordem da concupiscência como uma ordem civil que dispensa a ação da virtude como princípio: a concupiscência, deixando-se determinar de um modo mecânico, produz um efeito mecânico que é a força de um partido dominante, o poder político que sustenta a ordem civil. Para tanto, não foi preciso nenhuma astúcia ou habilidade particular dos grandes, o partido dominante, nem tampouco dos dominados; nenhuma virtude, moral ou política, de uma parte ou outra. Os grandes são grandes, insiste Pascal no primeiro dos Três Discursos sobre os Grandes, por acaso. Diríamos: pelo movimento das concupiscências e não pela capacidade de escolha que caracteriza a virtude.

\section{Referências Bibliográficas}

AGOSTINHO. La Cité de Dieu. In: (Bibliothèque de la Pléiade). . Lo Spirito e la Lettera. In: Città Nuova Editrice, 1991. . O Espírito e a Letra In: . A Graça. I. São Paulo: Paulus, 1999. . Euvres. II Paris: Gallimard, 2000. . O livre arbitrio. São Paulo: Paulus, 1995.

ARQUILLIERE, H.-X. L'augustinisme politique, essai sur la formation des théories politiques du moyen-age. Paris: Vrin, 1972.

DESGRIPPES, G. Études sur Pascal, de l'automatisme à la foi. Paris: Pierre Tequi, 1935.

GILSON, E. Les métamorphoses de la Cité de Dieu. Paris: Vrin, 1952.

LAZZERI, C. Force et Justice dans la Politique de Pascal. Paris: PUF, 1993. 
MESNARD, J. Le thème des trois ordres. In: HELLER, L. M.; RICHMOND, I. M. (Ed.). Pascal: Thématique des Pensées. Paris: J. Vrin, 1988.

NOVAES, M. Vontade e Contra-vontade. In: Novaes, A. (Org.). O avesso da liberdade. São Paulo: Cia. da Letras, 2002.

PASCAL, B. Euvres. Ed. Lafuma. Paris: Seuil, 1963. . Pensamentos. São Paulo: Martins Fontes, 2001.

PERCHEMAN, M. L'ordre dans les trois ordres et l'ordre des trois ordres. Révue de Métaphysique et de Morale, n. 1, jan./mars 1997.

SELLIER, P. Pascal et Saint Augustin. Paris: Armand Colin, 1970. 